\title{
Possibilidades e desafios do trabalho e da profissão de professoras na escola
}

\section{Liliana Soares Ferreira*}

\section{Resumo}

O artigo sistematiza estudo realizado com professoras de Ensino Fundamental no Sul do Brasil, buscando analisar os sentidos evidenciados em seus discursos sobre trabalho e profissão na escola. Buscou-se compreender como esses sujeitos se revelam ou não profissionais em sua condição de mulheres-professoras e como encaminham seu trabalho pedagógico na escola. Com base nesses sentidos, elaborou-se um percurso pelo qual, acredita-se, sistematizaram-se características da escola, como efetivo espaço e tempo de constituição profissional para essas mulheres, tendo como base as relações de gênero, a historicidade, as crenças, e, neste tempo e espaço, recuperam-se os sentidos e desejos que movimentam e constituem os sujeitos e o trabalho pedagógico.

Palavras-chave: Trabalho pedagógico. Profissão. Escola.

\footnotetext{
* Doutora em Educação pela Universidade Federal do Rio Grande do Sul (UFRGS). Professora do Programa de Pósgraduação em Educação e do Programa de Pós-graduação em Educação Profissional e Tecnológica da Universidade Federal de Santa Maria (UFSM).
} 


\section{Introdução ${ }^{1}$}

O trabalho com educação implica uma atividade de reflexão e sistematização contínua, que tenho realizado no cotidiano de instituições educacionais. De modo particular, para mim, o trabalho dos professores tem sido sugestivo para fins de estudos, principalmente se for considerado na sociedade contemporânea, que apresenta particularidades determinadas por fatores históricos, sociais e culturais. Trata-se de uma sociedade que se recompõe, reorganiza, cotidianamente, diante das contínuas descobertas científicas que, não raro, acabam por desfazer crenças e articular novos modos de compreensão; uma sociedade cujos metabolismos se apresentam desafiadores e não têm privilegiado a educação como prioridade, mas, ao contrário, utilizam a educação para o atendimento de necessidades imediatas, quais sejam, as relativas ao processo de produção de mercadorias em uma perspectiva inspirada pelo ideário neoliberal e pelo modo flexível das relações produtivas. Nesse contexto, o trabalho sofre alterações contínuas, indagando o sujeito acerca de si como trabalhador e redimensionando as relações emprego/desemprego. A cultura, da mesma maneira, tornou-se uma elaboração bastante sofisticada, mediada pela ciência e pelas transformações sociais. Para fins da discussão ora proposta, consideram-se os aspectos sociais como síntese do histórico e cultural e como determinantes e transformadores dos discursos sobre educação, passando a estabelecer os valores que fazem parte da elaboração subjetiva dos sujeitos.

Assim, em busca de respostas a muitas perguntas, há tempo, dedico-me a estudar sobre a profissão e o trabalho de professora/professor. Este interesse advém, também, do fato de pertencer a uma família de professores e de ser professora de professores. Em meu trabalho cotidiano, estou, continuamente, participando de ações educativas profissionais e conversando acerca da práxis pedagógica. Práxis pedagógica é o trabalho dos professores na organização, implementação e avaliação cotidiana da produção do conhecimento. Dentro da escola, a práxis é (ou deveria ser) pedagógica, pois a escola se constitui com e a partir do pedagógico. O pedagógico revela como "o grupo que compõe a escola se organiza regularmente e como entende e produz a educação. Transita entre o individual e o coletivo, dialeticamente, elaborando-se e acontecendo cotidianamente na escola" (FERREIRA, 2008, p. 183). Do mesmo modo, a práxis pedagógica constitui-se como o trabalho profissional dos professores e, nessa perspectiva, torna-se científica, por isso, metódica, sistemática, hermeneuticamente elaborada e teoricamente sustentada. Pode se dizer uma práxis pedagógica, então, uma práxis social, porque

\footnotetext{
${ }^{1}$ Trabalho de pesquisa desenvolvido com financiamento Edital Universal MCTI/CNPq No 14/2014; Edital Ciências Humanas, Sociais e Sociais Aplicadas MCTI/CNPQ/MEC/CAPES No 22/2014; Edital Pesquisador Gaúcho 02/2014 FAPERGS.
}

PERSPECTIVA, Florianópolis, v. 35, n. 2, p. 560-577,abr./jun. 2017 http://www.perspectiva.ufsc.br 
coletivamente "[...] elaborada e organizada conforme intencionalidades, conhecimentos" (FERREIRA, 2008, p. 184).

Atenta ao cotidiano escolar e às demandas de conhecer que continuamente nele se geram, realizei pesquisa qualitativa, um estudo (entendido como uma investigação em que tanto investigadores quanto interlocutores buscam compreender o seu fazer em um ambiente específico, revelado em seus discursos sobre este fazer), no intuito de entender os sentidos presentes nos discursos de professoras do Ensino Fundamental, Anos Iniciais, acerca de seu trabalho na escola. Foram entrevistadas vinte e duas professoras da Região Fronteira Noroeste do Estado do Rio Grande do Sul. As entrevistas foram gravadas, transcritas e analisadas. A seleção para compor o grupo de interlocução foi semialeatória. Convidei professores, em escolas pré-selecionadas. Participaram vinte e cinco professoras e, por nenhum homem ter escolhido participar da pesquisa, passei a analisar os sentidos com base também nesta perspectiva: estava trabalhando com uma população feminina e, portanto, havia um critério de gênero a ser considerado. Daí porque, durante o texto, refiro-me aos interlocutores como professoras. As interlocutoras atendiam a alguns critérios que utilizei para compor o grupo: serem licenciadas ou estarem cursando uma licenciatura, estarem interessadas em refletir sobre sua profissão e trabalharem em uma escola na Região pesquisada. A propósito, delimitei uma Região e cito-a como evidência cultural, pois não desconheço viver-se em uma sociedade tida como mundializada. Entretanto, também entendo serem as evidências culturais elementos presentes nos discursos dos profissionais. Durante a pesquisa, passei a conhecer o grupo e a identificar outras características semelhantes entre as professoras: trabalham em escolas cuja infraestrutura é deficitária, apresentam carência de material e tempos para produzir o trabalho pedagógico. Explica-se o sentido de trabalho pedagógico:

[...] o trabalho pedagógico é a categoria central tanto na organização da escola, expresso em seu projeto pedagógico, quanto no conhecimento resultante dos processos realizados na instituição. Daí porque urge aprofundar a compreensão dessa categoria, estabelecendo mais claramente suas características e, sobretudo, implicações. (FRIZZO; RIBAS; FERREIRA, 2013, p. 563).

Por ser pedagógico, o trabalho dos professores reveste-se de uma intencionalidade, portanto, é político por excelência. Frisa-se a crença de que somente é pedagógico por resultar de um projeto próprio, que articula crenças, experiências, fazeres selecionados pelo sujeito. Denomina-se essa elaboração de projeto pedagógico individual, mas entende-se ser dialeticamente construído entre o individual e coletivo, referendando-se e consubstanciando-se coletivamente. Por assim ser, a originalidade deste projeto é relativa, uma vez que resulta de uma historicidade, é substrato cultural, porém é assumida por um sujeito, em meio ao grupo, também historicamente construído e cujo trabalho 
se produzirá no entremeio entre suas crenças e a com-vivência. Portanto, a originalidade está nas escolhas reiteradamente realizadas. Daí seu caráter eminentemente político.

Considerei fundamental compreender como os sujeitos-professores se representam em seu trabalho, atendendo aos imperativos sociais e culturais que foram constituindo uma nova realidade social. Pensando nisso, procurei viabilizar um entendimento sobre o valor simbólico do trabalho dos professores evidenciado em seus discursos. Assim, busquei entendimentos acerca das posições nos discursos, que revelavam os sujeitos. Posições, como já disse, marcadas pela subjetividade, pelas relações de gênero e pela inclusão em um ambiente social.

Foi necessário gravar as entrevistas e, posteriormente, transcrevê-las e examinar o material transcrito, tendo em vista as anotações e sínteses elaboradas durante o processo. Após, foram formados grupos de interlocução ${ }^{1}$. No grupo, aprofundaram-se as reflexões, trazendo-se noções, aportes teóricos para dissipar dúvidas. Houve exposição aos participantes sobre as observações feitas e proposição de análise dos resultados obtidos até então. Considerei esta fase determinante no processo interpretativo dos discursos, pois havia um altíssimo grau de subjetividade em todo o trabalho de investigação proposto. Por isto, foi procedente dialogar sobre as interpretações com os próprios sujeitos, analisando, juntos, as opções teóricas determinantes deste ou daquele sentido. Tenho clareza que é constante a tensão entre objetividade e intersubjetividade, uma vez que discursos são fruto de seleção e, ao mesmo tempo, revelam o falante, por isto considero a interpretação no grupo de interlocução sempre um processo dialógico e, portanto, criativo.

Assim, o problema sobre o qual me propus pesquisar diz respeito ao trabalho como professora, ao ser alguém cujo trabalho, que é a produção da aula e, nela, a produção do conhecimento, que em meio a um contexto histórico-social lhe exige agir politicamente, compõe a sua profissão. Analisar os discursos das professoras sobre trabalho e escola implicou envolver-se com as profissionais, como sujeitos de uma historicidade que as orienta. Entender os efeitos de sentidos manifestos nos discursos das professoras aconteceu em um contexto que, como pesquisadora, fui delimitando, pois não seria possível isolar este objeto de todos os demais, dinamicamente, imbricados no espaço e no tempo da profissão.

Estes aspectos compuseram o aporte teórico e metodológico, de orientação crítica, que teve como suporte o conceito de trabalho. Na elaboração da problematização, já se estabeleceram categorias a priori, quais sejam: trabalho dos professores, trabalho pedagógico, escola e conhecimento. Tais categorias, associadas às categorias que caracterizam o Materialismo Histórico e Dialético, sobretudo 
historicidade, contradição, mediação, práxis, compuseram uma espécie de lente, pela qual os dados foram produzidos e analisados.

A pesquisa foi, então, um estudo dos discursos, inicialmente isolados, depois verticalizados, e, agora, nesta sistematização, percebendo-os integrados e, com isto, acabando por desvelar aspectos básicos sobre o trabalho e a escola, passo a apresentá-los, organizando-os em uma sequência, sem predominância ou sentidos mais relevantes de um item em relação aos outros, apenas como uma maneira considerada mais facilmente compreensível. Penso que tal sequência se constitui em uma possibilidade de a escola melhor se organizar com vistas a ser efetivo espaço e tempo de educação continuada para a profissão.

\section{Primeiro: sujeitos e historicidade}

Como já mencionado, foi composto um grupo de professoras, consideradas como representantes de um grupo social maior: os professores de Anos Iniciais do Ensino Fundamental da Região, trabalhadores da educação, inseridos em uma sociedade capitalista, tida como globalizada e neoliberal. Ao entrevistá-las, pode-se conhecer seus discursos sobre sua profissão, seu trabalho e sobre a escola, seu local de trabalho. Estes três elementos foram analisados como se estivessem imbricados por uma lógica: a professora é a trabalhadora da educação, denota características que revelam sua pertença ${ }^{2}$ a uma profissão, e tem na escola seu lócus profissional principal. Tive como hipótese que a profissão seria o estágio em que as profissionais sentir-se-iam impregnadas por seu fazer, por suas crenças e conhecimento de sua profissão, de modo a revelarem-se profissionais, o que gera demandas contínuas de compreender e envidar lutas dentro do contexto socioeconômico onde se inserem como sujeitos de um trabalho.

Os discursos remeteram a organizar uma sequência de análise. Parti de como as professoras se tornaram professoras, seu trabalho, sua profissão e as relações de gênero e classe social, chegando à escola, lugar onde estes temas se evidenciam. Nesta perspectiva, encontrei as professoras como trabalhadoras não denotando a dimensão social de sua profissão, ora porque preferem se alienar em discursos ideologizados, como o da vocação, da missão, do prolongamento da família; ora porque não refletiram sobre suas condições de trabalho e, também, como as anteriores, não têm como se revelar como trabalhadoras. Foram poucos os discursos, quatro apenas, fazendo menção às condições profissionais da professora como uma trabalhadora em meio a um sistema capitalista e, ainda nestes casos, sem aprofundamento, como se indicassem desconhecimento. Do mesmo modo, foram poucos os discursos, dois apenas, nos quais se percebia aproximação com uma professora atenta à sua profissão, 
aos problemas enfrentados pelos sujeitos-professores em relação às políticas educacionais e ao contexto social e, com base nestas compreensões, realizando seu trabalho, e sentindo-se agir socialmente.

Uma evidência marcante foi o fato de as professoras não enfatizarem os sentidos de "profissional" e de "profissão" como suas características, nem denotarem ser profunda a reflexão sobre seu fazer cotidiano, nem sobre sua condição e o entendimento de professora como trabalhadora em uma sociedade marcada por desigualdades sociais. É como se vivessem o trabalho, mas não existissem totalmente como profissionais, como trabalhadoras. Preferem esconder-se em um aparente trabalho voluntário, cujos ganhos são suportáveis, pois o que está acima de tudo é a oportunidade de trabalhar em prol de crenças na sociedade como espaço sem conflitos. Suas vidas como trabalhadoras justificamse por não estarem apegadas ao salário: “Eu estou (riso)... eu sou professora, porque eu quis ser professora, sabe? Eu lutei pra ser professora. Eu não sou professora pelo salário". (PROFESSORA 03). Este é apenas um elemento a mais. Tal evidência é demasiadamente significativa em um espaço em que se fala tanto em "professores qualificados, educação continuada e permanente" como demandas atribuídas isoladamente ao sujeito, isentando a responsabilidade do Estado e do próprio sistema educacional por esta tão propalada "qualidade" em educação. Tanto empenho e exigência são plausíveis quando os sentidos da profissão ainda estão no âmbito da doação? Uma primeira descoberta, para mim, foi esta: parece estar obnubilada, no universo imaginário das professoras entrevistadas, uma demanda real de estudo. Sua profissão está dada pelo que constituiu até agora, na academia, na vida, na escola. Isto está bastando. Não foram percebidas demandas de mudança, de renovados efeitos de sentidos para o trabalho, como algo imanente à elaboração contínua, rumo a uma profissão, como um devir, para além do cumprimento de exigências cotidianas de pontuações a serem atingidas em acordo com a frequência a cursos determinados pelo sistema educacional.

Os discursos levaram-me a pensar que, se a profissão é vista como pronta, o trabalho é repetitivo, renovado apenas quando recebe uma dica, uma sugestão que não exija esforço de estudo; e a escola, um lugar de repetição de fazeres considerados como certos, inflexibilizados. Buscar alterações salariais em luta organizada se faz distante, porque o trabalho é leve, o salário suportável, a escola é uma família. Deste modo, os discursos parecem indicar professoras impossibilitadas de superar a repetição, a rotinização e reencontrarem-se com sua profissão.

Nos grupos de interlocução discutiu-se com as entrevistadas esses sentidos e chegou-se a uma elaboração coletiva diferente. Considerando-se a condição profissional como elaborada a partir de sua historicidade, ampliando-se com sua vida acadêmica, em cursos de Magistério (Ensino Médio) ou em licenciaturas e, efetivamente, constituindo-se como característica do trabalho na escola, tornar-se 
professora implica bem mais que frequência a cursos, estágios, processos formais de educação continuada; implica um conjunto de sentidos presentes no âmbito do social, incluindo a família, a comunidade, a igreja. Na vida acadêmica, a profissional encontra espaço para refletir e teorizar sobre sua profissão, aprendendo a compreender, propor, analisar e criticar durante o seu trabalho pedagógico. Porém, é na escola que acontecem os efetivos processos constituidores, pois a professora, em conjunto com seus pares, passa a agir, refletir e sistematizar, elaborar linguagem sobre o seu fazer, elaborando conhecimentos profissionais, entendimentos, ações.

Então, o mero investimento em cursos, em palestras, em oficinas não constitui a professora. São demandados efetivos processos de educação continuada com vistas à produção de saberes e conhecimentos profissionais, mais que o simples domínio de conhecimentos da área de trabalho; implicam análise, reflexão, síntese de conhecimentos dos mundos da experiência e da ciência, com base na linguagem, sobre a qual se assentam como a maneira de compreender e agir no mundo, de entender e sistematizar, de interagir e produzir conhecimentos.

Certamente, as escolas não são espaços sociais ingênuos, porque, pautadas por escolhas, estruturadas em valores e em acordo com políticas, estão alicerçadas em estruturas ideológicas. A professora, sozinha, não tem condições de enfrentar estas estruturas, necessitando de auxílio para tornálas menos excludentes, mais humanas e efetivamente em acordo com as demandas da comunidade. Seria, sim, ingênuo acreditar que a professora, sozinha, pode modificar uma escola.

Como lugar de trabalho, pra mim, a escola é o lugar onde eu encontro, principalmente, o sujeito de relação, né? É nesse lugar que eu tenho essa possibilidade, essa oportunidade de interagir com o sujeito, e, acima de tudo, a questão do aprender e de me colocar neste lugar enquanto aprendiz, me relacionando também com o aprendente que é o educando. (PROFESSORA 10).

A redefinição da escola, de seus alicerces e crenças somente acontece se promovida pelo grupo de professores, organizada em torno de um projeto. O primeiro passo então é propor. Em torno da proposta se organizam grupos e estes, sim, podem alterar um espaço escolar. Para tanto, o diálogo, o respeito mútuo, a possibilidade de os projetos serem socializados sem melindres, de modo a convocar todos para uma ação que lhe é benéfica são exigências

A superação da ingenuidade é, portanto, coletiva. Os discursos das professoras, em grande parte, demonstram a não superação. Como podem se não têm espaço suficiente para diálogo, para convivência, para aprenderem juntas dentro da escola? Somente nesta perspectiva se pode configurar a elaboração da condição profissional como um contradiscurso contínuo, uma autorreflexão e uma reflexão, pressupondo um ambiente escolar onde é possibilitado o diálogo. Com este diálogo, os 
sentidos são desvelados, reelaborados e se tornam um pensar sobre e a partir da práxis, pois a profissão de professora está assentada em iniciativas a partir da escola, facilmente realizáveis se garantidos os espaços e tempos para os professores, com seus pares, reencontrarem-se e elaborarem juntos renovados sentidos de trabalho.

\section{Segundo: sujeitos-mulheres-professoras, relações pouco estudadas}

Observo que ainda são poucos os estudos que relacionam a educação às relações de gênero, sobretudo nos relativos ao trabalho dos professores. Esta minimização da importância destes estudos tem um fundamento histórico que, brevemente, descrevo.

No período anterior ao século XIX, no Brasil, as professoras eram raras, a educação feminina era centrada no aprendizado das "prendas domésticas", e, afora tal oportunidade, havia uma situação interessante: se por um lado, nas incipientes e raras escolas normais, havia oportunidades para mulheres estudarem e trabalharem, os currículos eram diferentes, implicando diferenças salariais. Não havia escolas exclusivamente para mulheres, apenas conventos. Daí o reforço daquele costume familiar dos grandes proprietários de terra de destinar uma filha para ser integrante do clero. Esta teria oportunidade de estudar.

No estudo desse percurso histórico, encontrei a ampliação dos quadros de profissionais, somente a partir do século XX, no Brasil, quando houve uma inclusão significativa de mulheres no Magistério. O incentivo à frequência aos cursos normais como uma modalidade de estudo marcadamente feminina, capaz de garantir uma profissão e, simultaneamente, uma oportunidade de intervenção social, além da proliferação de ordens religiosas femininas, cuja ação predominante era a educação e a saúde, foram as causas da instalação, em todo o país, de uma acentuada quantidade de cursos destinados à educação para a ação.

Obviamente, entre os trabalhadores, de modo geral, sempre houve uma grande parcela feminina, sobretudo em alguns setores de produção, como o têxtil. Hoje, diversificou-se e abrange outras modalidades de trabalho. O trabalho, na percepção de Antunes (2005a, p. 203), foi se configurando assim porque "[...] o capital percebeu que a mulher exerce atividades polivalentes, no trabalho doméstico e, além dele, no trabalho fora de casa, o capital tem utilizado e explorado intensamente essa polivalência do trabalho da mulher”. A dupla e até tripla jornada de trabalho, em casa e fora dela, não é novidade no caso da professora, cuja habilidade em realizar a aula e garantir a continuidade da rotina da família é algo cotidiano. Quem, como eu, é filha de professora, sabe que a estas mulheres está 
predestinado o lugar de ampliar funções além da casa, sem se descuidar desta. Tal caracterização também é aplicável a outras trabalhadoras, em outras profissões.

De certo modo, a urbanização acelerada e a industrialização contribuíram para estas evidências, na medida em que foram o palco para uma maior distinção entre trabalho de mulher e de homem. Naquela primeira metade de século, ainda cabia aos homens a atividade de maior exigência, tanto intelectual quanto física, e às mulheres, consideradas mais frágeis, uma ação na qual sua sensibilidade, fragilidade e feminilidade fossem pré-requisitos. Neste caso, uma categorização do trabalho feminino, não explicitada socialmente, mas evidente no imaginário social, era ser um subemprego, não descrito através das exigências de força, ousadia, capacidades intelectuais mais apuradas. Em meio a esta aparência do trabalho, tido como diferente em razão do gênero, que o Magistério se solidifica e se amplia como profissão. Mais um motivo para compreender melhor a categoria gênero, relacionando-a à profissão da professora.

Hypólito (1997, p. 55) confirma esta argumentação, defendendo que a feminização do Magistério acontece em meio ao desenvolvimento industrial e urbano do país, fenômenos correspondentes à formação social e econômica capitalista. Instrução não era o objetivo das camadas populares, pois não resultava em ascensão social imediata. Neste âmbito, ingressar no mundo do trabalho como professora foi uma oportunidade de as mulheres elaborarem um viés de participação social compatível com suas feminilidade e maternidade, em ambiente cultural e social adequado. Entre estas, Hypolito (1997, p. 55) considera a similaridade entre ser professora e ser mãe, as características femininas propícias para o cuidado de crianças, a compatibilização entre o horário do labor e a possibilidade de conciliá-lo com o de casa, o reconhecimento social. Tais explicações, oriundas do social, como se pode perceber, são bastante tendenciosas e compelem as mulheres a acreditarem na sua "vocação" para o Magistério: "Você tem que ter uma vocação, também acima de tudo você precisa ter a vocação". (PROFESSORA 05). Além disso, facilitam em muito a percepção do Magistério como a realização de uma aspiração: ser trabalhadora, desempenhar uma ação social, ter um salário e continuar sendo mãe, esposa e dona-de-casa.

Tal espaço para o que passou a ser chamado de feminização do Magistério acontece à medida que os homens passam a dedicar-se a outros fazeres. Torna-se cada vez menos frequente, a partir da segunda metade do século XIX, no Brasil, encontrar homens como professores dos Anos Iniciais do Ensino Fundamental. Aos homens, passa a caber qualquer atividade, sobretudo nos Anos Finais do Ensino Fundamental e Ensino Médio, além de serem, normalmente, os que assumem as funções técnicas: diretores, administradores etc. Sob esta perspectiva, a feminização do Magistério se apresenta 
como a ocupação de um lugar menor, aquele que aos homens não interessa mais. Ora, se entre os homens o Magistério já era uma profissão “menor”, para as mulheres não foi diferente:

[...] é de se supor que a docência passe a ocupar entre elas o mesmo lugar que ocupa entre os homens: um lugar de segunda categoria, inferior a carreiras profissionais de maior prestígio, mais bem-remuneradas ou, simplesmente, com maiores e melhores oportunidades de promoção para as mais ambiciosas. (ENGUITA, 2004, p. 111).

Apple ratifica este quadro, ao relatar o processo de feminização no Magistério norte-americano, afirmando:

O trabalho da mulher é considerado, de alguma forma, inferior ou de menor status pelo simples fato de ser uma mulher quem o faz. Devido a essas condições, tem sido excepcionalmente difícil para as mulheres estabelecer o reconhecimento das qualificações necessárias à sua atividade remunerada e não remunerada. Têm de lutar não só contra a construção ideológica do trabalho feminino, mas também contra as tendências existentes à alteração tanto da própria atividade quanto dos padrões de autonomia e controle. (APPLE, 1995, p. 56).

Somem-se as alterações no mundo do trabalho urbanizado e industrializado. A analogia que se pode fazer é que o conhecimento, uma produção masculina ao longo da História, ao se tornar responsabilidade feminina e, simultaneamente, tornando-se atividade profissional feminina, passa a ser considerada uma atividade menor, tanto na organização quanto no salário. Está pressuposto aqui um preconceito, bastante difundido, principalmente na sociedade brasileira, patriarcal e machista, que o labor masculino tem maior relevância do que feminino. Este preconceito é explicado com base na configuração biológica do corpo feminino, tido como mais frágil e na subjetivação da mulher, a qual pode se emocionar facilmente, em detrimento do homem, que deve conter suas emoções. Hypólito (1997, p. 73) amplia esta descrição:

O processo de feminização do magistério coincide com o processo de transformação do trabalho docente em trabalho assalariado, controlado pelo Estado, submetido a formas de controle externas ao próprio processo de trabalho, retirando dos professores formas autônomas de controle sobre o quê e como ensinar. O processo de racionalização e parcelamento do trabalho docente é simultâneo à transformação desse trabalho em trabalho feminino.

O autor ajuda a compreender um movimento de expropriação da professora do direito de gerenciar seu trabalho, submetendo-se a políticas externas. Esta maneira de organizar o fazer coincide com a organização da fábrica, setorizada, hierarquizada, cabendo ao "chão-de-fábrica", como pejorativamente são chamados os trabalhadores, apenas obedecer e realizar um trabalho do qual não participam do planejamento, não foram mentores. Autonomia e identidade são atributos negados às professoras a partir deste momento, posto que se estabelece uma forma de organização e vistoria do 
trabalho "[...] através do relógio; dos incentivos monetários; pela pregação e pelo ensino; pela supressão de feiras e dias de folga - formaram-se novos hábitos de trabalho, e impôs-se uma nova disciplina do tempo. (THOMPSON, 1991, p. 76).

Paradoxalmente, o público feminino no Magistério aumentou significativamente. Até parece que houve uma conformação da profissional com esta situação de ser vista como menos. Hoje, sem dúvidas, os quadros do Magistério são majoritariamente femininos. E conhecer este aspecto é fundamental para entender o trabalho dos professores na escola.

\section{Terceiro: sujeitos e a escrita}

Muitos podem ser os espaços-tempos para a educação continuada na e a partir da práxis pedagógica. Particularmente, considero a produção de narrativas o início de quaisquer ações visando à constituição profissional.

A importância das narrativas decorre do fato de se considerar que um grupo se constitui a partir de seus sentidos, na soma de suas experiências, no simbólico registrado ao longo de sua historicidade. Conhecer este simbólico exige desvelá-lo pela linguagem, narrá-lo de modo a reconstituí-lo e reconhecer-se na historicidade do outro. Por isto, permear o cotidiano da escola pelas narrativas de cada integrante do grupo é um modo de renovar experiências de vida, aproximar as pessoas e elaborar renovados sentidos para o grupo e para a escola. Na mesma perspectiva, se afirmo que a profissão se constitui mais com base na sua historicidade do que nos estudos realizados na academia, é necessário investir na produção de narrativas como autorreflexão, de elaborações individuais sobre os pressupostos da profissão e, a partir daí, em situações de convivência e diálogo, ampliá-la. Com este percurso, a professora poderá perceber sua profissão como algo em si, elaborada a partir de si, uma mudança acontecida em decorrência dos sentidos produzidos em relação ao seu campo de trabalho e ao seu fazer.

Acredito que as professoras necessitam reencontrar-se com suas historicidades: por que optaram pelo Magistério? O que as torna professoras? O que as sustenta como professoras? Quais suas relações com o conhecimento?

Mais uma vez, as narrativas de vida são essenciais para que aconteça este reencontro, senão seu trabalho tende a tornar-se um mero repetir-se que pode ser alienante. A dicotomia entre a vontade de permanecer no já construído, mais confortável e conhecido, em detrimento da vontade de mudança, evidenciada nos discursos, remete à percepção que o conhecimento é uma entidade dogmática, 
operatória e distanciada da vida: o conhecimento está no plano das ideias, e a vida está no plano da prática, do concreto. Conhecimento e pessoas estão separados. Nem de longe, nesse estado, as professoras parecem imaginar que as pessoas são o resultado de suas perspectivas, articuladas com seus conhecimentos. Tanto é verdade que a maioria das professoras afirmou desejar aperfeiçoar seu conhecimento com cursos, quando poderiam propor conversar em seus grupos, analisar os seus saberes, refletir sobre o já aprendido. Não parecem conhecer sobre seus próprios processos de aprender, os conhecimentos já produzidos e estão em perigo de continuar repetindo infinitamente, sem reflexão e tempo para o aprender e o conhecer seus próprios conhecimentos. Uma, entretanto, parece transgredir essa verdade aparentemente considerada consenso: “O que facilita meu trabalho como professora é o convívio, com os outros professores, com os estudantes, e a... tomada de decisão que tu tem que ter dentro da sala de aula, eu acho que isso faz você ser professora" (PROFESSORA 08). Por isto, acredito que, reconstituindo a sua historicidade, as professoras encontrarão o esteio para sua contínua emancipação, sua autonomia e sua profissão, em decorrência, pois narrar é produzir sentidos e memória.

\section{Quarto: os sujeitos e os espaços de educação continuada na escola}

Além das narrativas, ponto primal para qualquer proposta de educação continuada e permanente de professores, cito ainda algumas outras possibilidades, cujo pressuposto é o trabalho em equipe na escola, pois não acredito em processos pedagógicos modificados, senão com estudos e esforços no coletivo dos professores. Esta reflexão deve ser o alicerce de todo a revitalização do trabalho dos professores.

Em todas as possibilidades que passo a apresentar para a educação continuada e permanente a partir da escola, considero as professoras como sujeitos dotados de linguagem e capazes de propor, criticar e agir.

- o trabalho coletivo: a escola é uma comunidade, agrega diferentes interesses, desejos, sonhos. Qualquer iniciativa que desconsidere esta evidência básica está fadada ao fracasso, pois não se sustenta e nem encontra ecos na escola. Assim, quaisquer propostas, ações pedagógicas e planejamentos necessitam ser elaborados, desde o início, com a comunidade escolar, considerando suas peculiaridades e demandas. 
- estudos cotidianos: estudar é ação cotidiana das professoras. Na verdade, alguns autores defendem que o profissional da educação é um estudante contínuo (MARQUES, 1988; FREIRE, 1985). No entanto, estudar com o grupo de trabalho dimensiona diferentemente os estudos, tornando-os estudos identificados com o trabalho pedagógico e possibilitadores de novas modalidades de práxis para o grupo.

- reflexão sobre o trabalho no trabalho: porque vive correndo entre escolas, entre horários escolares, entre idas e vindas, muitas vezes, as professoras nem sequer têm tempo para pensar sobre o que lhes acontece. Se, no ambiente escolar, forem criados momentos para a reflexão sobre o trabalho pedagógico garantir-se-ão, consequentemente, novos sentidos capazes de rearticular este trabalho, de promover novos e renovados sentidos para o grupo.

- transdisciplinaridade: muito se fala em interdisciplinaridade, desde a década de 1980. As escolas, de modo geral, elaboram planejamentos com o intuito de garantir a inter-relação entre os diferentes conhecimentos. Enquanto dedicam tempo e esforço para tanto, muitas vezes, evitam pensar que o importante são as reflexões sobre concepções e encaminhamentos do trabalho pedagógico como um todo, não esfaceladas em componentes curriculares. Pensar transdisciplinarmente a escola implica pensar a educação independentemente da área de conhecimento a que se dedicam os professores, mas como o espaço e tempo para a produção de conhecimentos.

- seminários socializadores: todo o movimento de produção de conhecimentos necessita ser sistematizado. Considerando a escola como local do aprender, os seminários para sistematização são excelentes para garantir a participação e o reconhecimento aos esforços individuais na produção de conhecimentos. Dimensionar os seminários como momentos de encontro é igualmente garantir que os professores se conheçam em seu trabalho, em suas concepções do trabalho pedagógico, em suas metas e objetivos e estimular a pesquisa no cotidiano pedagógico, como fundamento.

Todas as alternativas são espaços e tempos a mais, ofertados no grupo e no cotidiano do local de trabalho como oportunidades em que se processarão, simultaneamente, a interação, a reflexão e a sistematização sobre os fazeres pedagógicos, de modo a constituir a profissão. O grupo age como estímulo e suporte às aspirações individuais, pois, na verdade, sabe-se ser o próprio professor quem gerencia sua educação continuada e permanente, em acordo com seu desejo, muitas vezes, demandado pela escola ou demandado por sua subjetividade. Este agir é superior a quaisquer outras organizações do espaço escolar, na medida em que possibilita a superação da percepção dos professores como meros 
funcionários do Estado. Permite que os professores superem, também, a impressão generalizada de agirem como se estivessem gerando apenas o necessário para a garantia da continuidade do processo e gerando a ideia de divisão do trabalho simples, que envolve todos em um objetivo similar, muitas vezes encontrado em discursos tais como "por que fazer mais, se, ao final do mês, o salário é igual para todos?". Em um contexto assim dinamizado, os profissionais passam a agir, decidir o quê, como e quando produzir.

Nesta perspectiva, por sua condição de lugar social, a escola pode ser organizada em espaçostempos de relações interpessoais: as aulas, as reuniões, o momento do recreio e horas para estudo e planejamento. Nas últimas, acontecerão desde os discursos sobre si mesmo até o surgimento de uma espécie de empatia que poderá dar origem ao trabalho coletivo. Somente assim iniciam-se produções que poderão reorganizar o lugar social, a ação social e, em decorrência, o trabalho pedagógico dos professores. Com isso, acontecerá o investimento nas pessoas, como seres históricos, e com saberes e experiências, o que garantirá ao trabalho pedagógico maior consistência e consequência. Será uma nova configuração do trabalho, mais compatível com as demandas atuais.

A partir daí, dinamizam-se contextos de aprender dentro da escola. Não no sentido clássico: o aprender do estudante, a escola como lugar para o estudante aprender. Em um sentido renovado, que desmistifica o tradicional: os professores aprendendo no trabalho, pois, se os professores não aprenderem durante a práxis pedagógica, em uma atitude de estudo contínuo, na interação com os estudantes, haveria perda do sentido da profissão. É por isto a defesa de a escola constituir-se em local de aprender, sendo local de trabalho e de aprendizagem, criando as condições para os profissionais produzirem conhecimentos e sentirem-se livre para pensar e agir. Creio haver possibilidade de romper com a linearidade dos estudos para a constituição dos professores: uma sequência rígida de cursos cuja base epistemológica e metodológica nem sempre é compatível com a realidade das escolas e dos sistemas educacionais. Ao contrário, muitas vezes, acobertam idealizações distanciadas do real, tornando os professores recém-licenciados, por exemplo, sonhadores a enfrentar uma realidade adversa.

\section{Quinto: os sujeitos-professores e o seu projeto pedagógico individual}

O projeto pedagógico individual é a evidência das crenças, da elaboração profissional. Este projeto pode ter como objetivo principal recuperar os espaços-tempos para a prática da indignação e considerar a tão necessária renovação, a não aceitação do que está pronto, dogmatizado, instituído, mas renovar sentidos em contínuo. Frisei anteriormente o medo da repetição por ingenuidade. O passado, 
certamente, é um pressuposto para a compreensão do presente e encaminhamento do futuro. Porém, simplesmente repetir indefinidamente o passado não garante a ação dialética, possibilitadora de uma educação emancipadora, no sentido de libertação, renovação e diferenciação tanto do estudante quanto dos professores. Os professores trabalham em acordo com crenças, concepções e conhecimentos que elaboraram acerca de si e do seu trabalho. Portanto, de modo geral, elaboram um projeto pedagógico que está em consonância com sua historicidade, como descreve uma das professoras entrevistadas:

Ser professor, para mim, é alguém, é o sujeito, que assume a sociedade, porque ele vai preparar, ajudar, conduzir, somente professores de séries iniciais. Eu me reporto, porque ele vai trabalhar com o sujeito, com a cognição desse sujeito. (PROFESSORA 11)

$\mathrm{Na}$ escola, caberia socializar esses projetos e, com base neles, contribuir na elaboração do projeto pedagógico da instituição. Um movimento inverso ao que se tem proposto, objetivando partir dos pedagógicos individualizados para elaborar um pedagógico escolar, e não o contrário. Seria um modo não somente de valorizar os sujeitos que compõem a escola, mas de iniciar a discussão por aquele elemento que organiza o trabalho pedagógico escolar: o trabalho individual de cada professor.

\section{Sexto: considerações finais}

Em suma, no intuito de promover espaços e tempos para os professores se constituírem professores, acredita-se que, na escola, podem ser elaboradas condições para a recuperação dos sentidos da profissão, através, inicialmente, do resgate e socialização das narrativas de vida. Uma vez renovados seus sentidos como ser social e histórico, também na escola, os professores têm condições de iniciar processos de educação, tornando-se professores-pesquisadores, produzindo conhecimento também na práxis na escola, porque lá estão seus colegas, sua cultura de trabalho, os estudantes e a comunidade com a qual trabalham. Com estes processos, pode, então, elaborar seu projeto pedagógico individual e, a partir dele, participar da elaboração do projeto pedagógico da escola. A elaboração do projeto pedagógico individual, base epistêmico-metodológica da profissão, somente teria espaço e condições, uma vez recuperada a historicidade, envidados esforços de educação continuada e instaurado o espaço da prática da linguagem e da pesquisa cotidianas.

Importante ainda frisar que a educação é produzida com base em sentidos e, do mesmo modo, toda prática pedagógica gera sentidos. Por isto, acontece na dialogicidade, de modo que os professores que não dialogam sobre seu fazer, com o intuito de melhor compreender-se, de atribuir sentido ao como se constituem profissional da educação, ao seu conhecimento, acabam por reproduzir tão somente 
fazeres ou porque são simples, ou porque perderam o gosto pelo seu trabalho. É nisto que creio após ter ouvido e analisado os discursos das professoras-interlocutoras.

Esta pesquisa, agora, está provisoriamente concluída, outras etapas virão. A cada leitura, certamente, estará sendo reescrita, porque pesquisa é sempre assim, nunca fica pronta. Se, porventura, deste texto surgirem outras pesquisas, gerando outras compreensões do trabalho dos professores e destes como trabalhadores, sem dúvidas, já terei alcançado alguns de meus objetivos. Paralelamente, a pesquisa, em minha profissão, tornou-se momento de releitura do meu trabalho como professora que continuará, porque ser profissional é uma condição de nunca se sentir completa, uma eterna busca de sentidos em discursos, fazeres, seres.

\section{NOTAS}

1 Entende-se o grupo de interlocução como "[...] uma maneira de redimensionar diferentemente a pesquisa, extraindo-lhe a aparência de ser mero aproveitar-se do discurso da interlocutora e com a pesquisa se beneficiar, sem contribuir e sem socializar os resultados. Além do mais, é um encaminhamento da pesquisa capaz de torná-la atividade que congrega os sujeitos envolvidos, tendo a linguagem como ambiente da produção coletiva dos sentidos e do contínuo redimensionamento da ação, visando a encontrar respostas ao problema" (FERREIRA, 2006, p. 38).

${ }^{2}$ Pertença profissional é compreendida como "uma construção social, uma realidade sócio-histórica, produzida pela ação dos atores sociais. Nesse sentido, não é uma lista de atributos de base, definidos em sentido determinista. [...] Pautando-se nesses pressupostos, entende-se o processo de subjetivação dos professores não como exaurido em si, mas como uma fase de identificação do ser e sua relação com o meio" (AMARAL, 2012). Disponível em: <http://ppge.rswa.com.br/wp-content/uploads/2011/03/Cl\%C3\%A1udia-Let\%C3\%ADcia-de-Castro-doAmaral.pdf>. Acesso em: 28 dez. 2014.

\section{REFERÊNCIAS}

AMARAL, C. L. do. À procura de pertença profissional: as interfaces do trabalho nos discursos de egressos (as) do Curso de Letras Inglês da Universidade Federal de Santa Maria. 2010. 126f. Dissertação (Mestrado em Educação) - Universidade Federal de Santa Maria, Santa Maria, 2010. Disponível em: <http://ppge.rswa.com.br/wp-content/uploads/2011/03/Cl\%C3\%A1udiaLet\%C3\%ADcia-de-Castro-do-Amaral.pdf>. Acesso em: 28 fev. 2013.

ANTUNES, R. Os sentidos do trabalho. São Paulo: Boitempo, 2005.

APPLE, M. Trabalho docente e textos: economia política das relações de classe e de gênero em educação. Porto Alegre: Artes Médicas, 1995.

ENGUITA, M. Educar em tempos incertos. Porto Alegre: Artmed, 2004.

FERREIRA, L. S. Educação \& história. 3. ed. Ijuí: Unijuí, 2001. 
FERREIRA, L. S. Trabalho, profissionalidade e escola no discurso das professoras dos anos iniciais do ensino fundamental. 2006. 293f. Tese (Doutorado em Educação) - Universidade Federal do Rio Grande do Sul, Porto Alegre, 2006.

FERREIRA, L. S. Gestão do pedagógico: de qual pedagógico se fala? Currículo sem Fronteiras, v. 8, n. 2, p.176-189, jun./dez. 2008

FREIRE, P. A importância do ato de ler: em três artigos que se completam. 10. ed. São Paulo: Cortez, 1985.

FRIZZO, G. F. E; RIBAS, J. F. M; FERREIRA, L. S. A relação trabalho-educação na organização do trabalho pedagógico da escola capitalista. Educação, v. 38, n. 3, set./dez. 2013. p. 553-564. Disponível em: <http://cascavel.ufsm.br/revistas/ojs-2.2.2/index.php/reveducacao/article/view/8987> Acesso em: 21 dez. 2014.

HYPOLITO, A. L. M. Trabalho docente, classe social e relações de gênero. São Paulo: Papirus, 1997.

MARQUES, M. O. Conhecimento e educação. Ijuí: Unijuí, 1988.

THOMPSON, E. P. O tempo, a disciplina do trabalho e o capitalismo. In: SILVA, T. T. da. (Org.). Trabalho, Educação e Prática Social - Por uma teoria da formação humana. Porto Alegre: Artes Médicas, 1991. p. 44-93. 
Opportunities and challenges of the work and profession of school teachers

\begin{abstract}
Absctract
The article systematizes a study with elementary school teachers, in southern Brazil, in an effort to analyze the meanings revealed in their discourses about work and profession in schools. We sought to understand how these subjects do or do not reveal themselves as professionals in their condition as womenteachers and how they conduct their educational work in school. Based on these meanings, we developed a route by which it is believed that school characteristics are systematized as effective spaces and times of professional constitution for these women, based on gender relations, historicity, and beliefs. In this time and space, the teacehrs recover meanings and desires that drive and constitute the subjects and pedagogical work.
\end{abstract}

Keys-words: Pedagogical work. Profession. School.

\section{Liliana Soares Ferreira}

E-mail: anaililferreira@yahoo.com.br
Oportunidades y desafíos de trabajo y la enseñanza de la profesión docente en la escuela

\section{Resumen}

El presente artículo sistematiza un estudio con los maestros de la escuela primaria, en el sur de Brasil, buscando analizar los sentidos expresados en sus discursos sobre el trabajo y profesión en la escuela. Tratamos de entender cómo los profesionales se ven o no como profesionales, en especial, en su condición de ser mujeres maestras y cómo se identifican delante su actividad pedagógica en la escuela. En este contexto, realizamos un abordaje, que, creemos, sistematiza las características de la escuela como un efectivo espacio y tiempo de constitución profesional para estas mujeres, teniendo como base en las relaciones de género, la historicidad, las creencias, y, en este espacio y tiempo, se recuperan los sentidos y deseos que mueven y constituyen los sujetos y el trabajo pedagógico.

Palabras clave: Trabajo pedagógico. Profesión. Escuela.

Enviado em: 19/11/2015

Versão final recebida em: $28 / 10 / 2016$

Aprovado em: 03/11/2016 